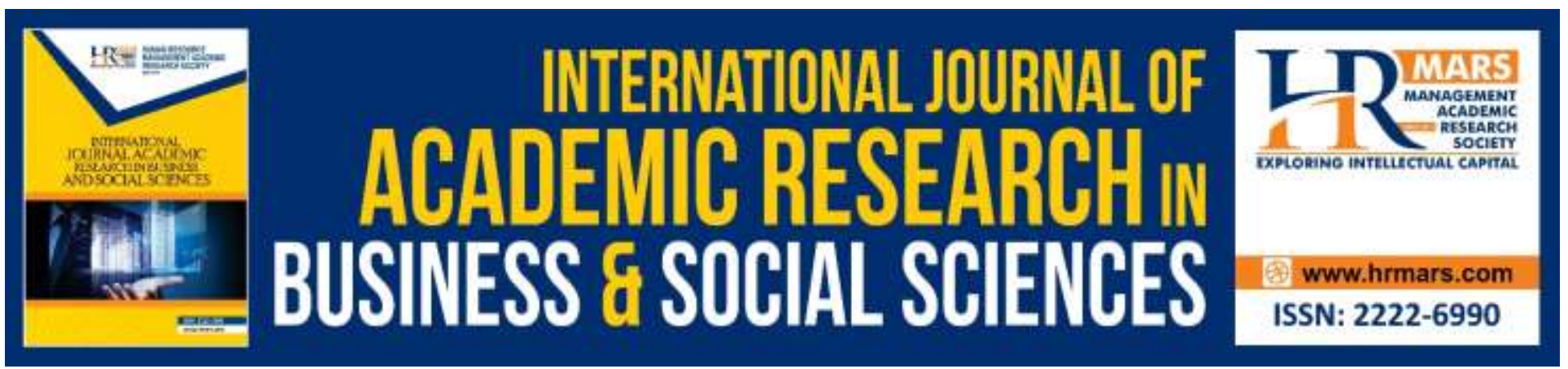

\title{
Digital Version for Obesity Predictor Instrument Among Adolescents
}

\author{
Zarizi Ab Rahman, Mawarni Mohamed, Mohamad Izwan Ismail, and \\ Ravichanthiran a/l Arujunan
}

To Link this Article: http://dx.doi.org/10.6007/IJARBSS/v9-i13/6246

DOI: $10.6007 /$ IJARBSS/v9-i13/6246

Received: 29 March 2019, Revised: 17 April 2019, Accepted: 02 July 2019

Published Online: 28 August 2019

In-Text Citation: (Rahman, Mohamed, Ismail, \& Arujunan, 2019)

To Cite this Article: Rahman, Z. A., Mohamed, M., Ismail, M. I., \& Arujunan, R. a/I. (2019). Digital Version for Obesity Predictor Instrument Among Adolescents. International Journal of Academic Research in Business and Social Sciences, 9(13), 96-106.

\section{Copyright: (C) 2019 The Author(s)}

Published by Human Resource Management Academic Research Society (www.hrmars.com)

This article is published under the Creative Commons Attribution (CC BY 4.0) license. Anyone may reproduce, distribute, translate and create derivative works of this article (for both commercial and non-commercial purposes), subject to full attribution to the original publication and authors. The full terms of this license may be seen

at: http://creativecommons.org/licences/by/4.0/legalcode

Special Issue: Revolutionizing Education: Challenges, Innovation, Collaboration, 2019, Pg. 96 - 106 http://hrmars.com/index.php/pages/detail/IJARBSS

Full Terms \& Conditions of access and use can be found at http://hrmars.com/index.php/pages/detail/publication-ethics 


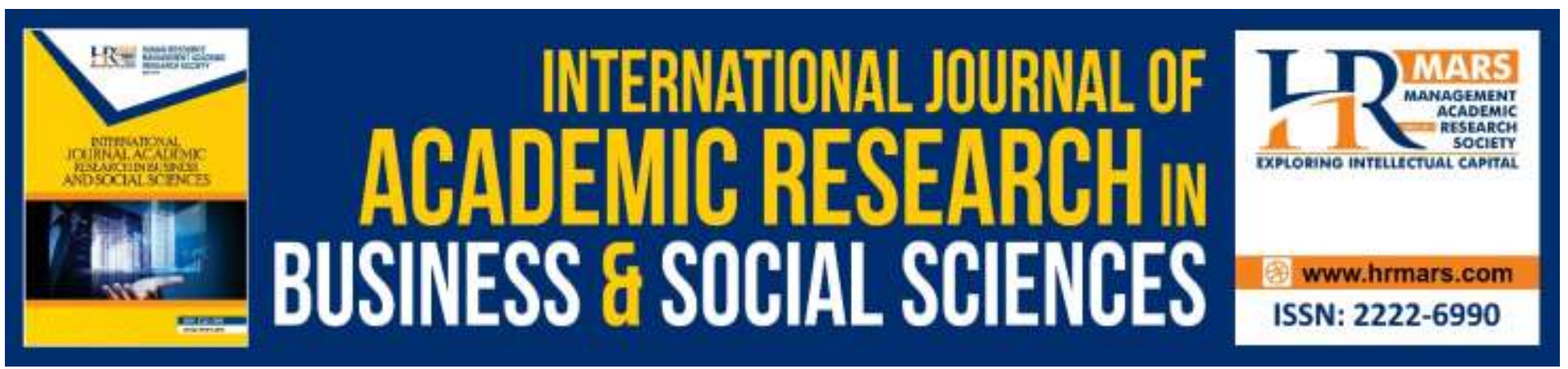

\section{Digital Version for Obesity Predictor Instrument Among Adolescents}

\section{Zarizi Ab Rahman ${ }^{1}$, Mawarni Mohamed¹, Mohamad Izwan Ismail², and Ravichanthiran a/l Arujunan ${ }^{3}$}

${ }^{1}$ Faculty of Education, Universiti Teknologi MARA, UiTM Puncak Alam Campus, 42300 Puncak Alam, Selangor, Malaysia

Email: zek1393@gmail.com, Mawarni@gmail.com

${ }^{2}$ Faculty of Applied Science, Universiti Teknologi MARA Cawangan Sarawak Kampus Mukah, 96400, Mukah, Malaysia

Email: izwanspp@gmail.com

${ }^{3}$ Institute Pendidikan Guru Kampus IImu Khas, Kuala Lumpur, Malaysia

Email: ravi@ipgkik.edu.my

Abstract: The rate of obesity among school children is increasing and at high risk for weight gain. Overweight and obesity occur when there is accumulation of body fat that presents a risk to health. Obese teens are more likely to become obese when they become adults and increase a risk of chronic diseases, including diabetes, cardiovascular diseases and cancer. Laboratory and field tests are two methods for measuring and screening tools for obesity percentage. However, field tests such as Body Mass Index, Bio Impedance Analysis and Skin Fold Test are more popular among researchers because of their ease of administration, inexpensiveness, portability and suitability for use in large populations. In schools, Body Mass Index is used to screen and determine obesity due to easy administration and inexpensive. However, Body Mass Index still needs high number of testers and takes a long time if it used for a large sample size. In this regard, Obesity Predictor Questionare can be applied as one of the methods to screen for obesity amongst students using 58 items which has undergone validity and reliability procedures. But how far can this method reach the population fast and effective? So, this study aims to develop Obesity Predictor Questionaire in the form of digital systems as Internet and smartphones are gaining in popularity with young population. The Digital Obesity Factor Questionaire can be used to screen directly to individuals with potentially favorable cost-utility and time consuming. The increased use of smartphones also create more dramatic shift in terms of speed and relevance. The development process involved deciding on specifications such as relevant guidelines, potential data collection; selecting the platform (Web-based); creating the design, which required decisions about the user interface, and programming code; and testing the prototype versions with the target audience. The system took 5 weeks to develop and 150 subjects 
provided qualitative and quantitave feedback about using the systems. Online version of Obesity Factor Questionaire is an innovative medium to screen obesity among school children nationwide.

Keywords: Chronic Diseases, Innovation, Internet, Obesity, Smartphone

\section{Introduction}

The obesity phenomenon has become alarming worldwide, especially among school children. Teens with a predisposition for obesity are more likely to become obese when they become adults. The Health and Mobility Survey (NHMS) reported in 2011 children and adolescents below eight years $3.9 \%$ (0.3 million) and 18 above $27.2 \%$ (4.4 million) were obese (Public Health Institute, 2013) while data from Global School Based Student Health Survey (2012), $19.1 \%$ of students aged 13-17 in Malaysia were overweight while $7.9 \%$ were obese (WHO, 2012). These findings can be interpreted that the rate of obesity among children and adolescents is at an alarming level. Obesity during the teen years is associated with many adverse health consequences which include greater rates of mortality as young adults (Engeland, Bjorge, Tverdal, \& Sogaard, 2004).

There are many factors and lifestyle behaviours that appear to play an important role in the etiology of weight gain in this population group such as physical activity behaviours, nutrition behaviours, socio economic behaviors, health knowledge, motor skill competency, level of fitness, built environment, self efficacy toward physical activity (Rahman, 2017; Hankinson, Daviglus, Bouchard, Carnethon, Lewis, Schreiner, \& Sidney, 2010; Duffey, Gordon-Larsen, Steffen, Jacobs Jr, \& Popkin, 2010).

Internet and smartphone development have become increasingly fast especially in the 21st century. This development has taken place throughout the world including developed and developing countries. In developed countries, an average person owns 1.18 smartphones with this number continuing to rise (Telecommunication Development Bureau, 2012). Approximately, there were 24.5 million Internet users, an increased from 24.1 million in 2015 (Internet User Survey, 2017) in Malaysia. According to the survey, the smartphone is also the most popular for users to access the internet. Additionally, in 2016, there were 28.5 million mobile broadband subscriptions compared to 2.5 million fixed broadband subscriptions. Based on the statistics, children in United States now are more likely to own a mobile phone than a book, with $85 \%$ of kids owning a phone as to only $73 \%$ owning books (Union, 2011). Without exception, Malaysia is one of the countries that has undergone changes in telecommunications evolution. It is reported the smartphone penetration rates grew by 7.2\% from 68.7\% in 2016 to 75.9\% in 2017(Malaysian Communications and Multimedia Commision, 2017).

The development of smartphones and internet has led to the enhancement of the software applications which is a program able to run on these devices. From the perspective of public health, smartphone and internet applications have the potential to enhance the delivery of health behaviour changes to individuals and cost effective compared with conventional methods. There are several physical health applications that have been developed by the commercial sector (Gan, \& AllmanFarinelli, 2011). Among the applications developed are physical activity, exercise methods, healthy eating, calorie counts and others. 


\section{Problem Statement}

There are a few method to measure and screen obesity which includes field and laboratory test. Most researchers use the field methods compared to laboratory methods to measure the level of obesity and the percentage of body fat because of easy administration, portable equipment, inexpensive and require less skillful testers. Hence, field methods such as Body Mass Index (BMI), skinfold test and Bio Impedance Analysis (BIA) are the choice of researchers apart from being used in large populations. Obesity Instrument Prediction (Zarizi Ab Rahman, 2017) is a set of questionnaires developed specifically for predicting obesity among adolescents. In addition, this instrument also serves as screening tool for overweight and obesity.

Apart from the validity and reliability, an instrument also needs to meet the ability to measure samples in large population and cost effective. The field method test instruments have meet these criteria, but some tests such as Skinfold and BIA also require high level of testing skills and expensive equipment. In this regard, BMI is the most popular instrument used in schools to determine the status of obesity among students. However, the use of BMI in large populations will involve the use of many testers and will take a long time. Therefore, an instrument which is reliable and valid to measure large samples at any time should be developed to facilitate the testing, measurement and evaluation processes. Hence, this study suggests the Obesity Instrument Prediction is used as an obesity screening tool for students in secondary schools. Various public health agencies propose the development of screening tools to predict likelihood of obesity in adolescents (Kraak, Liverman, Koplan, 2005; Krebs, Jacobson, 2003). The use of Obesity Instrument Prediction provides some of the benefits of saving time, costs, portability, and does not require a trained tester, which therefore minimizes objectivity issues. In addition, this instrument is suitable for large populations.

Therefore, it is necessary to develop digital version for Obesity Instrument Prediction to be used through smartphones and computers. Early detection of obesity especially in school allows interventions to be conducted by related parties. Teachers and parents who can detect early tendencies of obesity can plan specific intervention to prevent this issue to increase. Early detection and intervention is very important as obese children tend to become obese when they beome adults. Prevention theory suggests that prevention efforts need to begin early in the life before the risk for children increases (Ihmels, Welk, Eisenmann, \& Nusser, 2009).

There are various instruments developed to increase the awareness and measure of physical activity and healthy eating, but the instruments are more general and unable to predict adolescent's risk to become obese. Therefore, this study aims to develope the Digital Version Obesity Predictor Instrument as a screening tool. A behaviorally based screening tool was designed to assess behaviour, environment, and individual factors that may predispose adolescents to becoming overweight or obese. This paper also describes the process of developing digital version for Obesity Predictor among Adolescents. Besides that, this study also aims to establish the validity of the Obesity Instrument Predictor in the population studied.

\section{Literature Review}

The growth in the internet and the new media has also changed the lifestyle of people of all ages. Some of the new innovations are expected to change the human lifestyle today. Most people in our country practice the use of smart phones as one of their life syle. Most of the daily activities involve smart phones and internet. The use of online applications has become increasingly popular. 
According to the Internet User Survey 2017, 86.9\% of users relying on the internet to look for health information. The most common health related information seeked were on symptoms and diseases (91.4\%), health care tips (89.8\%) and treatment method (83.5\%). Accordingly, any application related to public health should be developed in line with current developments. Increase of internet and telecommunications users should be best used by researchers in public health.

There are various health and fitness online instruments and applications developed by many researchers. These applications are for people to use those purposes. The development of the online applications is also due to the changing lifestyle of today's internet-based applications. Cook, Farinelli, Ploeg, (2012) have developed applications for nutrition and physical activity for young adults. The application is developed through 4 processes namely; deciding on the behavior change strategies, relevant guidelines, graphic, design; selecting the platform (Web-based versus native); creating the design and programming code; and testing the prototype versions with the target audience. The study found that smartphone applications were an innovative medium for delivering individual health behaviors change to the community.

The Family Nutrition and Physical Activity (FNPA) Screening Tool is an online instrument was developed from an Academy of Nutrition and Dietetic Evidence Analysis (EA) that examined the factor related to childhood overweight. The FNPA screening tool was created as valid behaviourally based screening tools to identify family influences and behaviours that increases a child's like hood of becoming overweight. This instrument examines multiple domains including family diet, physical activity, screen time, sleep, and family schedule to provide a comprehensive evaluation of family environment. Research has shown that this screening tool can predict potential adverse changes in a child's risk for overweight (Ilhmels, Welk, Eisenmann, Nusser, \& Myers, 2009).

Obesity Predictor Instrument was developed by Zarizi Ab Rahman (2017) as a screening tool to predict obesity and overweight among adolescents. The instrument contains 11 domains based on Social Cognitive Theory to predict behaviors that are at risk of becoming obese like health knowledge, level of fitness, motor competence, self efficay, sedentary life style, nutrition behaviour, sosio economic, media, community, school, and family environment. According to Zarizi Ab Rahman (2017), the development of Obesity Prediction Instruments is based on the model proposed by Feren, Torheim, and Lillegaard, (2011). Seven experts in language, physical activity, and nutrition have been referred to determine the content validity of the instrument. The content validity for this instrument is $r=83$ and $r=87$. Cronbach Alpha was conducted to determined the internal consistency for the instrument. The result of the analysis show Alpha Cronbach Coefficient is $\alpha=.89$. While analysis factor was conduct to determine item validity for every domains. 
Table 1. Obesity Instrument Predictor

\begin{tabular}{ll}
\hline \multicolumn{1}{c}{ Domains } & \multicolumn{1}{c}{ Number of Items } \\
\hline Self-Efficacy & Q1, Q2, Q3, Q4, Q5, Q6, Q7, Q8, Q9 \\
Motor Competence & Q10, Q11, Q12, Q13, Q14, Q15, \\
& Q16 \\
School Environment & Q17, Q18, Q19, Q20, Q21 \\
Media & Q22, Q3, Q24, Q25 \\
Community environment & Q26, Q27, Q28, Q29, Q30, Q31 \\
Family environment & Q32, Q33, Q34 \\
Nutrition behavior & Q35, Q36, Q37, Q38, Q39 \\
Sedentary behavior & Q40, Q41, S42 \\
Knowledge & Q43, Q44, Q45, Q46, Q47, Q48, \\
& Q49 \\
Physical Fitness & Q50, Q51, Q52, Q53 \\
Socio economic & Q54, Q55, Q56, Q57, QS58 \\
\hline
\end{tabular}

Table 1 shows the domains and numbers of items in the instrument. There are 58 items to be answered by adolescents (item number 1-53) and parents (item number $54-58$ ). The items were coded on 5 point Likert Scale (1-Strongly disagree, 2- Disagree, 3- Undecided, 4- Agree, 5- Strongly agree). There are 46 negative items and need to reverse coded. All answers were added to create a total score for the whole screening tool. The number of scores was then used to predict obesity based on the Scale of Obesity Prediction (Zarizi Ab Rahman, 2017).

Table 2. Scale of Obesity Prediction

\begin{tabular}{cc}
\hline Category & Total Score \\
\hline Underweight & Below 116 \\
Normal & $117-175$ \\
Overweight & $176-234$ \\
Obese & Above 235 \\
\hline
\end{tabular}

Source : Zarizi Ab Rahman (2017). Development of Obesity Predictor Instrument. Thesis Ph.D. Faculty of Sport Science and Coaching, Universiti Pendidikan Sultan Idris.

The process that has been implemented to develop Obesity Predictor Instrument clearly illustrates that all procedures have been followed. Therefore, this instrument is acknowledged to have the validity and reliability to be used as a tool for obesity screening among adolescents. Nevertheless, the rapid development of technology, internet and communication makes the instrument more efficient in the form of digital to facilitate the process of screening for all parties. 


\section{Method}

The researchers adapted the method used by Hebden, Cook, Ploeg, \& Allman-Farinelli, (2012) to develop the digital version of Obesity Predictor Instrument.

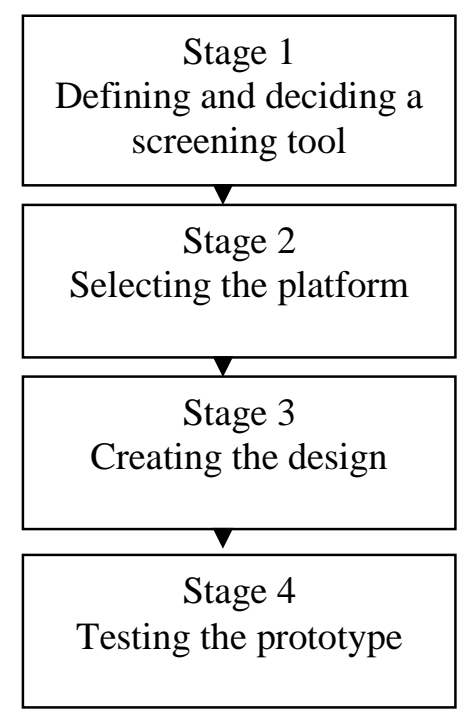

Diagram 1 : Model to develop digital version of Obesity Predictor Instrument

The development process of digital screening tools involved four stages consist of deciding on tools to predict obesity and relevant guidelines, potential data collection; selecting the platform (Web-based); tool design, which required decisions about the user interface, rules, formulas; and testing the prototype versions with the target audience.

The first stage involved defining and deciding the screening tools and purposes. There are various obesity-screening tools in the form of questionnaire, but Obesity Predictor Instrument is used because of the validity and reliability of the instrument. Additionally, the instrument also developed specifically for the local adolescent's population. Although there are various instruments from other countries, however these instruments are developed based on their population, which is different in cultures, life styles, educational systems and others. The differences make the data that is acquired may invalid and it is difficult to predict obesity among population studied. Digital Obesity Predictor Instrument is designed specifically to screen students at secondary school.

The second stage is to select a platform for this instrument to be accessed by the targeted population. These digital tools will use the web- based application so that users can access via smartphones and computers. A web-based application is an application that uses a website as the interface. Users can easily access the application from any computer or smartphone connected to the internet using standard browser. Other than that, this study uses web- based applications to avoid download external applications on their computers or smartphones. The third stage is to create design of digital instruments based on web - based application. There are sections of the application, which consist of home, about application, information, research, and us. The design of this application is user friendly to meet the target population of students in secondary schools. In the 
application section students will fill in the instrument and state the agreement for each question based on Likert Scale. The score will determine the risk of obesity. All studies related to this instrument are also included in the research section so users can make references.

The fourth stage is to test the prototypes in the pilot study. One hundred and fifty adolescents from SMK Seri Andalas, and SMK Rantau Panjang, Klang ( $N=62$ boys and N=88 girls) aged 13 to 14 years participated in the pilot study. The samples will fill in the online version of the Obesity Predicitor Instrumens to get their total scores. Researchers will measure the BMI of the same sample to compare obesity levels using online version Obesity Predictor Instrumen and BMI. A Pearson productmoment correlation coefficient was computed to assess concurrent validity of obesity factor predictors using BMI as a standardized instrument.

\section{Results and Discussion}

Mean score for Obesity Instrument Predictor is $(M=160.7, S D=41.91)$ and mean score for $\mathrm{BMI}$ is $\left(M=23.74 \mathrm{~kg} / \mathrm{m}^{2}, S D=9.0\right)$. Statistical analysis showed, there was a strong and positive correlation between the Obesity Instrument Predictor and BMI ( $r=0.90, n=150, p=0.00)$.

Table 3 : Descriptive Statistic Body Mass Index and Obesity Instrument Predictor

\begin{tabular}{lccc}
\hline & Mean & SD & $\mathrm{N}$ \\
\hline Body Mass Index & $23.74 \mathrm{~kg} / \mathrm{m}^{2}$ & 9.00 & 150 \\
$\begin{array}{l}\text { Score of Obesity Instrument } \\
\text { Predictor }\end{array}$ & 160.70 & 41.91 & 150 \\
\hline
\end{tabular}

Table 4 : Concurrent Validity Obesity Instrument Predictor

\begin{tabular}{cccc}
\hline & & BMI & $\begin{array}{c}\text { Obesity } \\
\text { Instrument } \\
\text { Predictor }\end{array}$ \\
\hline Body Mass & Pearson Correlation & 1 & $.899^{* *}$ \\
Index & Sig. (2-Tailed) & & .000 \\
& $\mathrm{~N}$ & 150 & 150 \\
\hline
\end{tabular}

**. Correlation Is Significant At The 0.01 Level (2-Tailed).

The findings show that Obesity Instrument Predictor can be used as an alternative instrument for determining obesity among adolescents. Thus, Obesity Instrument Predictor was digitalize as online screening tool. The tool took 5 weeks to build including creating the designs with information technology support, and testing the prototypes. 150 participants offered to use this digital instrument reported no difficulty while using the system. However there was a small number of participants complained that the system was slow on their mobile devices. This is due to slow internet connection. 
Table 5. Result of Body Mass Index

\begin{tabular}{ccc}
\hline Category & Total Score & Percentage \\
\hline Underweight & Below 18.49 & 36.7 \\
Normal & $18.50-24.99$ & 30.0 \\
Overweight & $25.00-30.00$ & 24.0 \\
Obese & Above 30.01 & 9.3 \\
\hline
\end{tabular}

Table 6. Result of Digital Version Predictor Instrument

\begin{tabular}{ccc}
\hline Category & Total Score & Percentage \\
\hline Underweight & Below 116 & 34.7 \\
Normal & $117-175$ & 32.0 \\
Overweight & $176-234$ & 24.0 \\
Obese & Above 235 & 9.3 \\
\hline
\end{tabular}

Tables 5 and 6 show the level of obesity based digital version Obesity Predictor Instrument and Body Mass Index. The study found that $34.7 \%$ and $36.7 \%$ of samples were categorized as underweight according to digital version Obesity Predictor Instrument and Body Mass Index. Whereas $32.0 \%$ and $30 \%$ in the normal category for digital version Obesity Predictor Instrument and Body Mass Index. A total of $24.0 \%$ of samples were categorized as overweight based on both instruments. While $9.3 \%$ of samples were categorized as obese by both instruments. In comparison, this finding is equivalent of each category for the online version Obesity Predictor Instrument and Body Mass Index. This shows that the digital version Obesity Predictor Instrument can be used to predict the obesity as predicted by the Body Mass Index. The study provides descriptive information and a comprehensive digital screening tool to predict the risk of adolescent overweight and obesity. A comparison was made between the Obesity Predictor Instrument constructs and BMI to examine validity and appropriateness of the tools. The comparison revealed the findings of Obesity Predictor Instrument and BMI are equal. This suggests that the constructs assessed in the Obesity Predictor Instrument tool capture aspects of the home/shared family environment and behaviours that also influence child BMI.

\section{Conclusions and Recommendation}

The results of the study have provided a very important implication in the context of testing, measurement and evaluation of obesity especially among children and adolescent in Malaysia. The digital instrument not only suitable for teachers in schools, but also for parents at home where they can use the instrument to monitor their childrens' obesity levels periodicaly. Regular monitoring by parents able to control the increase in body fat amongst their children. The role played by these parents can have a great impact on the health of their children. Accordingly, the digital version Obesity Predictor Instrument is an alternative method of Body Mass Index which can be used as a 
screening tool to predict obesity especially for large populations such as school children. Additionally, web based system makes it more easier to access these instruments. Teachers and parents just need to check the result that has been generated by the system. Digital version of Obesity Factor Questionaire is an innovative medium to screen obesity among school children nationwide.

This digital instrument also meets technology developments where most daily activities are done by online system. In conclusion, this instrument is able to reduce costs, facilitating the administration of the test, and capable to conduct in the large populations in a short time. A centralized database system can be developed in future studies, thus allowing findings of the studies to be accessed by the concerned parties such as Ministry of Education, State Education Department and schools in the country. These findings which can be readily accessed quickly and easily allow the parties concerned to plan interventions to reduce obesity among school children.

\section{References}

Cole-Lewis, H., \& Kershaw, T. (2010). Text messaging as a tool for behavior change in disease prevention and management. Epidemiologic reviews, 32(1), 56-69.

Duffey, K. J., Gordon-Larsen, P., Steffen, L. M., Jacobs Jr, D. R., \& Popkin, B. M. (2010). Drinking caloric beverages increases the risk of adverse cardiometabolic outcomes in the Coronary Artery Risk Development in Young Adults (CARDIA) Study. The American journal of clinical nutrition, 92(4), 954-959.

Engeland, A., Bjorge, T., Tverdal, A., \& Sogaard, A. J. (2004). Obesity in adolescence and adulthood and the risk of adult mortality. Epidemiology, 79-85.

Feren, A., Torheim, L., \& Lillegaard, I. L. (2011). Development of a nutrition knowledge questionnaire for obese adults. Food \& nutrition research, 55(1), 7271.

Fjeldsoe, B. S., Marshall, A. L., \& Miller, Y. D. (2009). Behavior change interventions delivered by mobile telephone short-message service. American journal of preventive medicine, 36(2), 165-173.

Gan, K. O., \& Allman-Farinelli, M. (2011). A scientific audit of smartphone applications for the management of obesity. Australian and New Zealand journal of public health, 35(3),293294.

Hankinson, A. L., Daviglus, M. L., Bouchard, C., Carnethon, M., Lewis, C. E., Schreiner, P. J.\& Sidney, S. (2010). Maintaining a high physical activity level over 20 years and weight gain. Jama, 304(23), 2603-2610.

International Telecommunication Union, The Little Data Book on Information and Communication Technology 2013, ITU and World Bank, p136. Retrieved from: issuu. com/world.bank.publications/docs/9780821398166?e=161 7657/3852706\#search

Kraak, V. A., Liverman, C. T., \& Koplan, J. P. (Eds.). (2005). Preventing childhood obesity: health in the balance. National Academies Press.

Krebs, N. F., \& Jacobson, M. S. (2003). Prevention of pediatric overweight and obesity. Pediatrics, 112(2), 424-430

Ihmels, M. A., Welk, G. J., Eisenmann, J. C., Nusser, S. M., \& Myers, E. F. (2009). Prediction of BMI change in young children with the family nutrition and physical activity (FNPA) screening tools. Annals of Behavioral Medicine, 38(1), 60-68. 
Ihmels, M. A., Welk, G. J., Eisenmann, J. C., \& Nusser, S. M. (2009). Development and preliminary validation of a Family Nutrition and Physical Activity (FNPA) screening tools tools tool. International Journal of Behavioral Nutrition and Physical Activity, 6(1), 14.

Malaysian Communications And Multimedia Commissionhand Phone Users Survey 2017. Retrived from : https://www.skmm.gov.my/skmmgovmy/media/General/pdf/HPUS2017.pdf

MCMC. MCMC Annual Report 2012 [Internet]. 2012. Retrived from: http://www.skmm. gov.my/skmmgovmy/media/General/pdf/MCMC_RET523-667P_ENGLISH_COMPLETE. pdf

Public Health Institute. (2013). National Health and Morbidity Survey 2011. Ministry of Health Malaysia

Schoffman, D. E., Turner-McGrievy, G., Jones, S. J., \& Wilcox, S. (2013). Mobile apps for pediatric obesity prevention and treatment, healthy eating, and physical activity promotion: just fun and games?. Translational behavioral medicine, 3(3), 320-325.

Telecommunication Development Bureau. (2012). Union, I.T. Global ICT Developments. 2011 Retrived from: http://www.itu.int/ITU-D/ict/statistics/ict/index.html

Featuring the Handphone Users Survey M. C. A. M. Commission, Editor (2007). Malaysian Communications and Multimedia Commission: Cyberjaya, Selangor Darul Ehsan.

WHO and CDC, Global School-based Student Health Survey-Malaysia. (2012) Fact Sheet. Retrieved from: www.who.int/chp/gshs/Malaysia_2012_GSHS_FS_national.pdf

Rahman, Z. A. (2017). Development of Obesity Predictor Instrument. Thesis Ph.D. Faculty of Sport Science and Coahing, Univerisiti Pendidikan Sultan Idris. 